\title{
DIREITOS DA SOCIOBIODIVERSIDADE: a exploração dos conhecimentos tradicionais sob uma perspectiva de ecocidadania.
}

\author{
Matheus Silva De Gregori ${ }^{1}$ \\ Isabel Christine Silva De Gregori ${ }^{2}$
}

\begin{abstract}
RESUMO: Este artigo tem como objetivo analisar a realidade em torno da exploração da sociobiodiversidade no contexto da globalização e da hegemonia econômica dos países desenvolvidos. Observa-se que no decurso da expansão do sistema econômico globalizado ocorrem processos de apropriação indevida dos métodos de exploração dos recursos naturais pelas empresas multinacionais, restando aos autênticos detentores dessa variedade de saberes - as comunidades tradicionais - uma situação de submissão e exclusão, visto que ficam à margem desta dinâmica de mercado. Este processo se realiza pela apropriação dos direitos intelectuais relativos a estes conhecimentos, mostrando-se necessária uma reflexão da visão jurídica acerca da sociobidiversidade. Buscou-se desenvolver uma análise relativamente às possibilidades de emancipação dessas comunidades, dentro de um paradigma de biocêntrismo e eco-cidadania.
\end{abstract}

PALAVRAS-CHAVE: Sociobiodiversidade. Conhecimentos tradicionais. Globalização. Ecocidadania.

\section{RIGHTS OF SOCIOBIODIVERSITY IN THE CONTEXT OF GLOBALIZATION: the exploitation of traditional knowledge from the perspective of eco-citizenship.}

\begin{abstract}
This article aims to analyze the reality surrounding the socio-biodiversity in the context of globalization and economic hegemony of developed countries. It is observed that during the expansion of the globalized economic system processes occur misappropriation of the methods of exploitation of natural resources by multinational companies, leaving the genuine holders of the range of knowledge - the traditional communities - a situation of subjugation and exclusion, as become marginalized in this dynamic market. This process is done through the appropriation of intellectual property rights relating to this knowledge, being necessary to consider the legal view on the sociobidiversity. We sought to develop an analysis on the possibilities of emancipation of those communities within a paradigm biocentrism and eco-citizenship.
\end{abstract}

KEY-WORDS: Sociobiodiversity. Traditional knowledge. Globalization. Eco-citizenship.

\section{ASPECTOS INTRODUTÓRIOS}

Pode-se constatar, a partir de uma análise dos ecossistemas do planeta Terra, a existência de uma notável diversidade biológica dos países tropicais, sobretudo em territórios

\footnotetext{
${ }^{1}$ Autor - Acadêmico do $3^{\circ}$ semestre do curso de Direito - Universidade Federal de Santa Maria, participante do Grupo de Pesquisa de Direitos da Sociobiodiversidade - GPDS/UFSM.

${ }^{2}$ Orientadora. Doutora em Desenvolvimento Regional. Professora adjunta do Departamento de Direito da UFSM.
} 
da América Latina, África, Índia, dentre outros países que, coincidentemente, fizeram (ou ainda fazem) parte dos processos de colonização e exploração que resultaram na delineação Norte-Sul característica da ordem capitalista globalizada.

É interessante ter em conta que esta variedade biológica converte-se, por diferentes processos, não só em diversidade cultural, como também em distintas formas de uso, apropriação e exploração do território, evidenciando, além do grande potencial, a necessidade de preservação da sociobiodiversidade decorrente desta interação sociedade/meio-ambiente.

Relevou-se neste trabalho a necessidade de reflexão acerca dessa realidade, a partir da superação do paradigma cartesiano-linear, substituindo-o pela perspectiva sistêmica e permitindo, assim, um enfoque holístico do meio ambiente, que questione a visão antropocêntrica na relação homem-natureza, possibilitando um desenvolvimento econômico menos monopolizado, pautado no equilíbrio, na preservação da diversidade ecológica e social e na sustentabilidade.

Desse modo, atentando para a atualidade e importância deste tema, corroborada pela iniciativa da ONU em que se considerou 2010 como o Ano Internacional da Biodiversidade, e tendo em conta todas as diretrizes propostas em torno desta convenção ${ }^{3}$, este artigo propõe-se a questionar a atual perspectiva de visão jurídica em torno dos direitos da sociobiodiversidade, tendo em vista possibilitar a emancipação dos povos que se encontram em uma situação de submissão após terem sido cingidos pelo contexto da Globalização Econômica. Dentro desse panorama objetivar-se-ia a harmonia da relação entre bens e serviços gerados a partir de recursos naturais, e a formação de cadeias produtivas que respeitem a realidade histórica dos povos e comunidades tradicionais e possibilitem a consolidação da ecocidadania ${ }^{4}$ no mundo globalizado.

\footnotetext{
${ }^{3}$ Disponível em http://www.peaunesco.com.br/BIO2010/Diretrizes_Gerais\%20\%20Ano\%20Internacional\%20da\%20Biodiversidade\%20-\%202010.pdf. Acesso em 10/04/2011.

${ }^{4} \mathrm{O}$ conceito e ecocidadania ou cidadania ecológica utilizado na pesquisa corresponde à definição elaborada por Mark J Smith (1998), no qual se considera a necessidade de mudança dos pressupostos éticos convencionais, substituindo os valores antropocêntricos pelos ecocêntricos e criando, assim, novas possibilidades para se alterar a relação entre a sociedade e a natureza.
} 


\section{SOCIOBIODIVERSIDADE E HEGEMONIA ECONÔMICA PÓS-MODERNA}

Estima-se que em torno de $50 \%$ a $60 \%$ de toda a variedade de formas de vida do planeta encontram-se concentradas na região compreendida pelo ecossistema amazônico, sendo que apenas metade destas são conhecidas pela ciência. Juntamente com os países compreendidos pela floresta amazônica, outros diversos territórios, mais especificamente os tropicais, estão entre aqueles considerados como países megadiversos ${ }^{5}$. O Brasil se destaca, com larga liderança neste aspecto, na medida em que detém comprovada preeminência em termos de biodiversidade.

Ocorre que, a partir de uma visão que supere o paradigma antropocêntrico, se observa que na medida em que o ser humano entra em contato com o meio ambiente a sua volta, na intenção de satisfazer seu instinto de sobrevivência, ele cria uma relação de mútua troca com o ecossistema, representando, assim, mais um "personagem" dentro da teia que mantém o equilíbrio por meio dos processos cíclicos da natureza ${ }^{6}$. Esta seria a essência do pensamento biocêntrico.

Como conseqüências dos diferentes povos em interação com os múltiplos biomas ao redor do planeta, apresentam-se as mais variadas formas de exploração e apropriação do território, ou seja, a multiplicidade de biodiversidade corresponde, mais ou menos proporcionalmente, em variedade de sociobiodiversidade. Como melhor exemplo disso, podese citar novamente a realidade brasileira, que compreende mais de duzentos povos indígenas, além de diversas comunidades tradicionais, entre extrativistas, pescadores, quilombolas, agricultores familiares, etc. que são detentores de vasto conhecimento associado aos ecossistemas dentro dos quais estão circunscritos. Explica Antônio Diegues (2009, p.32) que "a biodiversidade pertence tanto ao domínio do natural como do cultural, mas é a cultura

\footnotetext{
${ }^{5} \mathrm{O}$ instituto executivo The United Nations Environment Programme's World Conservation Monitoring Centre (UNEP-WCMC), classificou, no ano 2000, 17 países como considerados megadiversos. Estes seriam, na ordem de quantidade de biodiversidade, os seguintes: Brasil, Indonésia, África do Sul, Colômbia, Austrália, Papua Nova-Guiné, México, China, Filipinas, Madagascar, Índia, Malásia, Venezuela, Peru, Equador, EUA e Zaire. Juntos estes territórios abrangem mais de $70 \%$ da biodiversidade do planeta. Gráfico disponível em http://www.environment.gov.au/soe/2001/publications/theme-reports/biodiversity/biodiversity01-3.html

${ }^{6}$ O conceito de teia foi utilizado por Fritjof Capra (2001) dentro da perspectiva de uma visão de mundo holística, a partir da proposição de um novo paradigma conhecido como Ecologia Profunda.
} 
enquanto conhecimento que permite às populações tradicionais entendê-la, representá-la mentalmente, manuseá-la.”

Diante do comprovado potencial de crescimento econômico por meio da exploração desses conhecimentos associados, apresenta-se a complicada e lamentável realidade de apropriação desregulamentada dessas riquezas, restando aos povos detentores da primazia desses saberes a condição de dependência e impotência em relação aos grupos dominantes.

Isso se deve, indubitavelmente, a realidade do capitalismo no contexto da Globalização econômica e da chamada Pós-modernidade. Esta última, concebida por Harvey (2002, p. 111-112), autor responsável pela formulação de uma definição muito aceita acerca desde conceito, a condição pós-moderna,

[...] com sua ênfase na efemeridade da jouissance, sua insistência na impenetrabilidade do outro, [...] sua preferência pela estética, em vez da ética, leva as coisas longe de mais. Ele as conduz para além do ponto em que acaba a política coerente, enquanto a corrente que busca uma acomodação pacífica com o mercado o envereda firmemente pelo caminho de uma cultura empreendimentista que é o marco do neoconservadorismo reacionário. O pós-modernismo quer que aceitemos as reificações e partições, celebrando a atividade de mascaramento e de simulação, todos os fetichismos de localidade, de lugar ou de grupo social, enquanto nega o tipo de metateoria capaz de apreender os processos político-econômicos (fluxos de dinheiro, divisões internacionais do trabalho, mercados financeiros, etc.) que estão se tornando cada vez mais universalizantes em sua profundidade, intensidade, alcance e poder sobra a vida cotidiana. Pior do que isso, enquanto abre uma perspectiva radical mediante o reconhecimento da autenticidade de outras vozes, o pensamento pós-moderno veda imediatamente essas outras vozes o acesso a fontes mais universais de poder, circunscrevendo-as num gueto de alteridade opaca, da especificidade de um ou outro jogo de linguagem. Por conseguinte, ele priva de poder essas vozes (de mulheres, de minorias étnicas e raciais, de povos colonizados, de desempregados, de jovens etc.) num mundo de relações de poder assimétricas.

Com isso, tendo em vista atender a dinâmica do mercado, dentro de uma condição geral da contemporaneidade em um contexto pós-moderno, impõe-se uma lógica onde o aspecto financeiro assume uma importância hiperbólica, em detrimento da matéria social, cultural e, principalmente, ambiental.

Neste processo, identifica-se a padronização do conhecimento, na medida em que só é válida aquela sabedoria e aquele método de produção que passaram pelo crivo da ciência, mais especificamente, da ciência a partir de uma perspectiva "ocidentalizada", do "Norte", dos países de "primeiro mudo". Como conseqüência, o conhecimento na área de biotecnologia acaba sendo totalmente voltado para a maximização da produção e do lucro, ou 
seja, o critério não é investir no que faz bem as pessoas e ao meio ambiente, mas sim em tudo o que pode ser patenteado e vendido.

Essa tendência de atender os grandes mercados internacionais por um único produto acabou gerando as grandes áreas de monocultura, que, ao substituírem a vegetação original, reduzem a biodiversidade e põem em risco a própria produção de alimentos, uma vez que os vegetais ficam mais vulneráveis a pragas e doenças. Dentro da realidade da América Latina, e de todos os outros países em desenvolvimento determinados a serem os "fornecedores" de gêneros primários ao resto do mundo, esses problemas se tornam ainda piores, como alerta Vandana Shiva (2000), na medida em que os sistemas tradicionais são substituídos por monoculturas que resultam na extinção de inúmeras espécies de seres vivos, além do uso abusivo de agrotóxicos, que criam novos problemas de saúde para a população rural.

Deste modo, para Araújo (2010, p.302):

\begin{abstract}
[...] se hace necessário analizar los avances tecnológicos que se propone la agricultura, en especial, verificar hasta que punto la biotecnologia tiene uma relación próxima a los pressupuestos ecológicos o si no esta solamente subyugada a los dictámenes del mercado. Ciertamente, esto significa una reflexión ética sobre las relaciones existentes entre el mundo de la producción agrícola, el medioambiente y el mercado.
\end{abstract}

Dentro deste cenário, Boaventura de Sousa Santos (2005) reconhece a distinção entre dois campos da globalização: o hegemônico, alinhado aos princípios neoliberais do Consenso de Washington, que preceituam a restrição da regulamentação estatal da economia, a afirmação de direitos de propriedade intelectual a investidores estrangeiros (submissão das inovações à propriedade intelectual) e a subordinação dos Estados-Nações à tutela de instituições como o Banco Mundial, o Fundo Monetário Internacional (FMI) e a Organização Mundial do Comércio (OMC). Essas seriam as globalizações de-cima-para-baixo ou hegemônicas, exemplificadas pelo autor como "localismos globalizados" e "globalismos localizados". Por outro lado, questões acerca do cosmopolitismo e patrimônio comum da humanidade seriam as globalizações de-baixo-para-cima, ou contra-hegemônicas, como, por exemplo, o que é observado por Santos (2003, p.56) através do imperativo cultural, segundo o qual "as pessoas e os grupos sociais têm o direito a ser iguais quando a diferença os inferioriza, e o direito a ser diferentes quando a igualdade os descaracteriza". 
Na esteira do discurso contra-hegemônico, a atual dinâmica de mercado pós-moderna começa a ser vista de outra maneira. Reconhece-se o outro lado da moeda, ou seja, o lado inverso ao do crescimento econômico quando se trata do embate entre o conhecimento científico e o saber das comunidades tradicionais. Evidencia-se, por exemplo, que, após as empresas de cosméticos e laboratórios concentrarem pelos processos industriais os estratos das plantas e vegetais encontrados na natureza, elas instauram os processos de patenteamento e propriedade intelectual sobre o produto produzido, tendo em vista resguardar seu "investimento" e toda a possibilidade de lucro em torno dele. Acontece que, muito antes deste processo de industrialização, o conhecimento acerca destes recursos, bem como a maneira de utilizar os efeitos conferidos por eles, já eram oferecidos pela natureza e utilizados tradicionalmente pelas comunidades locais, o que representa uma perda de direitos que já existiam costumeiramente para esses povos.

Este processo converte-se no que se conhece como "Etnobioprospecção", que consiste justamente na prática de empresas multinacionais para a busca e investigação do conhecimento de povos tradicionais acerca do uso que fazem dos recursos disponíveis dentro do bioma que os cerca a fim de identificar as propriedades terapêuticas ou cosméticas destes para posterior extração e comercialização privada. Mesmo na maioria das vezes sem resultar em contraprestação aos verdadeiros detentores dos direitos intelectuais, esta prática resulta em larga prosperidade econômica às corporações bioquímicas, na medida em que potencializa a eficiência dos recursos naturais, como exposto por Vandana Shiva (2001, p.101):

Dos 120 princípios ativos atualmente isolados na medicina moderna, 75\% têm utilidades que foram identificadas pelos sistemas tradicionais. Menos de doze são sintetizados por modificações químicas simples; o resto é extraído diretamente de plantas e depois purificado. Diz-se que o uso do conhecimento tradicional aumenta a eficiência de reconhecer as propriedades medicinais de plantas em mais de $400 \%$.

Entretanto, dentro do discurso hegemônico dos cientistas do Norte, atribui-se a responsabilidade da redução da biodiversidade aos países do Sul, justificando, desta forma, a intervenção de instituições internacionais com o objetivo de apropriação dos saberes e conhecimentos locais necessários para a identificação das espécies e suas propriedades terapêuticas e medicinais. Essa dinâmica é denominada por Boaventura de Sousa Santos 
(2005) de "imperialismo ecológico" ou "bioimperialismo", dentro de um contexto de interação que reproduz as relações coloniais do período moderno.

Diante desta realidade, é pertinente relatar algumas das medidas que já foram tomadas, tanto em âmbito nacional como internacional, tendo em vista amenizar os efeitos nocivos da configuração atual.

\section{MECANISMOS DE DEFESA E PROTEÇÃO DA SOCIOBIODIVERSIDADE}

Pode-se dizer, a título de conhecimento histórico, que a primeira medida de proteção ambiental em terras brasileiras estava contida nas Ordenações Manuelinas, de 1521, que abrangiam algumas condições de caráter protecionista. Após, em 1830, foi promulgado o Código Criminal que estabelecia em seu artigo 178 e 257 as penas para quem efetivasse o corte ilegal de madeiras. Porém, o período de consolidação da legislação ambiental no Brasil só ocorreria na década de 1930. É neste período que se destaca a produção de normas com temáticas ambientais mais específicas, como o primeiro Código Florestal brasileiro, instituído pelo Decreto 23.793, de 23 de janeiro de 1934, o primeiro Código das Águas, por meio do decreto 24.643, de 10 de julho de 1934 e o Código de Mineração, instituído pelo decreto-lei 1.985, de 29 de janeiro 1940.

Entretanto, a partir da Convenção de Estocolmo de 1972, que representou um marco internacional relativamente à preocupação com o Meio Ambiente e as mudanças climáticas, e as convenções que se seguiram após esta, é que ficou evidente a necessidade de existência de legislações que coíbam a apropriação ilícita da biodiversidade, bem como protejam e estimulem a exploração sustentável desta.

A maior conquista neste sentido, sem dúvida, é a Lei $\mathrm{N}^{\circ} 6.938^{7}$, de 31 de agosto de 1981, que dispõe sobre a Política Nacional do Meio Ambiente, bem como o artigo $225^{8}$, de nossa Constituição Federal. Este último representa um capítulo inteiro dedicado ao Meio Ambiente, indicando relevante avanço da legislação brasileira. Posteriormente, legislou-se

\footnotetext{
${ }^{7}$ Disponível em http://www.mma.gov.br/port/conama/legiabre.cfm?codlegi=313. Acesso em 04/01/2012

${ }^{8}$ Disponível em http://www.planalto.gov.br/ccivil_03/constituicao/constitui\%C3\%A7ao.htm. Acesso em 04/01/2012
} 
para regulamentar este artigo, o que não impede a constatação de que ainda falta aplicabilidade ao art. 225, no que temos ainda muito a avançar.

Ainda, destaca-se com larga relevância a Convenção sobre Diversidade Biológica ${ }^{9}$ (CBD), criada em 1992 durante a Rio-92 $2^{10}$, que estabelece normas e princípios que devem reger o uso e a proteção da biodiversidade dos países signatários. De modo geral, a CDB propõe regras para garantir a conservação da diversidade biológica, o seu uso sustentável e a justa repartição dos benefícios provenientes da exploração econômica dos recursos genéticos das espécies, respeitada a soberania das nações sobre o patrimônio existente em seu território. A CBD já foi assinada por 168 países, e 188 países a ratificaram, incluindo o Brasil ${ }^{11}$, sendo o primeiro país a ratificar o tratado.

A despeito do que foi acordado pela $\mathrm{CDB}$, dois anos depois ocorreria a criação do Acordo TRIPs $^{12}$ (ou Acordo ADPIC, de 1994), aparecendo não só como grande instrumento multilateral para a globalização das leis de propriedade intelectual mas também como criador da Organização Mundial do Comércio (OMC). Facilitou-se, assim, o controle da dinâmica de mercado pelas grandes corporações e pelos detentores do capital, e "legitimou-se" o processo perverso da biopirataria.

Apresenta-se como ponto de dissonância entre a CDB e o tratado internacional TRIPSs o fato da CDB estabelecer princípios de repartição justa e equitativa dos benefícios e a valorização dos conhecimentos tradicionais, enquanto o sistema de patentes do TRIPs assegura o monopólio e a propriedade àquele que detém e desenvolve novas tecnologias e

\footnotetext{
${ }^{9}$ Disponível na íntegra em http://www.onu-brasil.org.br/doc_cdb.php. Acesso em 12/04/2011

${ }^{10}$ A ECO-92, Rio-92, Cúpula ou Cimeira da Terra são nomes pelos quais é mais conhecida a Conferência das Nações Unidas sobre o Meio Ambiente e o Desenvolvimento (CNUMAD), realizada entre 3 e 14 de junho de 1992 no Rio de Janeiro. O seu objetivo principal era buscar meios de conciliar o desenvolvimento sócio-econômico com a conservação e proteção dos ecossistemas da Terra.

${ }^{11}$ Pelo Decreto Legislativo n²/1994, disponível em http://www.mct.gov.br/index.php/content/view/14925.html. A promulgação se deu pelo Decreto $\mathrm{N}^{\circ} 2.519$ de 16 de março de 1998, disponível em http://www.planalto.gov.br/ccivil_03/decreto/D2519.htm. Acesso em 12/04/11.
}

${ }^{12}$ O Acordo TRIPs (do inglês Agreement on Trade-Related Aspects of Intellectual Property Rights) é integrante do conjunto de acordos assinados em 1994 que encerrou a Rodada Uruguai e criou a Organização Mundial do Comércio. Também chamado de Acordo Relativo aos Aspectos do Direito da Propriedade Intelectual Relacionados com o Comércio (ADPIC). Disponível em http://www.cultura.gov.br/site/wpcontent/uploads/2008/02/ac_trips.pdf. Acesso em 12/04/11 
produtos, inclusive os provenientes da diversidade biológica acessada por meio da sabedoria das comunidades tradicionais.

A aplicação da CDB tanto entre os países megadiversos como nos países detentores de recursos tecnológicos encontra dificuldades para avançar, tendo em vista que grandes potências, como os EUA, não ratificaram esse tratado e, portanto, não são obrigados a respeitar, e como de fato, não respeitam os princípios da Convenção.

Em âmbito nacional, pode se destacar a Medida Provisória $n^{\circ} 2.186-16 / 2001^{13}$, que foi editada justamente para regulamentar os princípios propostos pela CDB. Esta MP trata acerca do acesso ao componente do patrimônio genético e aos Conhecimentos Tradicionais Associados, além de disciplinar a repartição justa e equitativa dos benefícios derivados da exploração destes recursos e o acesso e transferência de tecnologias que auxiliem na conservação e utilização da biodiversidade. Como iniciativa política para aplicação da CDB, o governo brasileiro instituiu planos estratégicos ${ }^{14}$ para conservação da biodiversidade, destacando-se, mais recentemente o Plano Nacional de Promoção das Cadeias de Produtos da Sociobiodiversidade ${ }^{15}$.

Ainda que estas medidas representem um obstáculo à desapropriação ilícita da sociobiodiversidade, resta claro a necessidade de reflexão em torno do modelo econômico atual, tendo em vista o desenvolvimento de uma visão crítica e a proposição de um paradigma que possibilite o desenvolvimento sustentável e a cidadania ecológica.

\section{PERSPECTIVA SISTÊMICO-COMPLEXA, DESMONOPOLIZAÇÃO ECONÔMICA E A CONSTRUÇÃO DA ECOCIDADANIA}

A mudança de pensamento econômico pelo ambiental/social passa, necessariamente, por uma mudança de paradigma, mais especificamente, do paradigma reducionista-

\footnotetext{
${ }^{13}$ Disponível em http://www.planalto.gov.br/ccivil 03/mpv/2186-16.htm. Acesso em 12/04/2011.

${ }^{14}$ Como exemplo, tem-se o Projeto de Conservação e Utilização Sustentável da Diversidade Biológica Brasileira (PROBIO) e o Programa Nacional da Diversidade Biológica (PRONABIO).

${ }^{15}$ Disponível em http://comunidades.mda.gov.br/portal/saf/arquivos/view/sociobiodiversidade/PLANO_NACIONAL_DA_SOCI OBIODIVERSIDADE-_julho-2009.pdf. Acesso em 12/04/2011.
} 
mecanicista (cartesiano-linear) para o sistêmico-complexo. O primeiro caracteriza-se por propor uma visão mecanicista do conhecimento, composta de várias partes que se unem. Assim, para entender o funcionamento de um sistema (seja uma máquina, um objeto ou uma sociedade), é preciso fragmentá-lo para conhecer suas funções, ou seja, vai-se do todo para as partes. Por outro lado, como explicado por Capra (2001, p. 41),

[...] na abordagem sistêmica as propriedades das partes podem ser entendidas apenas a partir da organização do todo. Em conseqüência disso, o pensamento sistêmico concentra-se não em blocos de construção básicos, mas em princípios de organização básicos. O pensamento sistêmico é "contextual", o que é o oposto do pensamento analítico. A análise significa isolar alguma coisa a fim de entendê-la; o pensamento sistêmico significa colocá-la no contexto de um todo mais amplo.

A partir da adoção da perspectiva sistêmica pelos líderes políticos, cientistas, empresários, etc, possibilitar-se-ia novos rumos dentro da pesquisa e desenvolvimento da biotecnologia, porquanto a natureza não seria vista como objeto de controle ou mera fonte de matéria prima, mas sim como mentora e fonte de aprendizado. "Em vez de tratar a teia da vida como mercadoria," aduz Capra (2003. p. 212), "respeitá-la-íamos como o próprio contexto em que se desenrola a nossa existência”.

Dentro deste contexto, é imprescindível ressaltar a perspectiva da ecosofia, elaborada por Félix Guattari (1990). Este autor propõe que a atitude ecosófica passa por três dimensões - ecologia mental, ecologia social e ecologia ambiental - com o objetivo de ressingularização do homem para "o pensar emancipatório", de modo que sua conduta individual agregue valores socialmente relevantes, e não só econômicos. Na medida em que sua subjetividade adquira o sentido de pertencimento ao grupo, a sua relação com a natureza adquire possibilidades de valorizações éticas, estéticas e sociais, podendo reinventá-la e superar a crise ambiental. Resta claro que observar o mundo a partir da perspectiva ecosófica coadunase com o significado da expressão sociobiodiversidade e a própria preservação desta.

Neste sentido, outro avanço essencial seria a consideração da complementaridade de saberes, por meio da supressão da rivalidade entre o saber científico e o tradicional. Para isso, seria imprescindível o reconhecimento dos conhecimentos culturais dos povos autóctones para o desenvolvimento e proteção da diversidade biológica, bem como conferir a essas formas de saber a autonomia necessária para a preservação e manutenção destes saberes. 
Aparece como alternativa o estabelecimento de um mecanismo que reconhece o valor intrínseco das diferentes formas de vida e o direito das comunidades diversificadas em permanecer com seu conhecimento acerca da flora e fauna que os entorna, indicada por Vandana Shiva (2003) como estrutura de "biodemocracia".

Em decorrência disso, a atual hegemonia cultural e a monopolização econômica dariam lugar a um maior desenvolvimento do poder local nos países em que se encontram conjunturas de sociobiodiversidade em uma situação de submissão. Seria a alternativa para um movimento de emancipação destes povos, pois no domínio humano, como coloca Capra (2003, p. 224), “a sustentabilidade é perfeitamente compatível com o respeito à integridade cultural e ao direito básico das comunidades à autodeterminação e à auto-organização".

A formação e o fomento de cadeias de produção em equilíbrio com a natureza e inseridas em um contexto social onde existe uma sabedoria passada de geração em geração iria não só possibilitar a independência econômica e cultural desses povos, como também desenvolver um método produtivo altamente renovável na medida em que, quanto maior a biodiversidade, maior a capacidade de regeneração dos ecossistemas. Dessa forma, além de produzir de uma maneira sustentável, essas “empresas" tradicionais poderiam inclusive se apresentar como competitivas no mercado internacional. Não no sentido de distribuírem seus produtos em todo globo, evidentemente, mas porque ninguém teria a capacidade de competir com elas no local onde estão instaladas.

Estas mudanças estruturais encontram obstáculos hoje por alguns motivos. O principal, como já foi visto, é a realidade das regras de livre comércio, concebidas e protegidas pela OMC tendo vista sufocar a capacidade de produção local para que esta seja substituída pela dinâmica da importação/exportação. Dinâmica esta que, cabe ressaltar, impõe um dano pesado ao meio ambiente porquanto promove uma poluição e um gasto imenso de energia nos processos de transporte de mercadorias e matérias-primas. Além disso, mostra-se necessária uma mudança de perspectiva, essencialmente no que tange o padrão de consumo, hoje altamente influenciado pela padronização promovida pela ocidentalização da cultura. Entra aí o conceito de Consumo Sustentável, representado pela necessidade de mudança nos padrões de consumo ${ }^{16}$, instituídos pela Agenda 21, outro resultado da conferência Rio-92 que é pouco aplicado na atualidade.

\footnotetext{
${ }^{16}$ Disponível em http://www.cqgp.sp.gov.br/gt licitacoes/publicacoes/AGENDA\%2021\%20GLOBAL\%20CAP\%C3\%8DTULO \%204.pdf. Acesso em 12/04/2011.
} 
Além disso, é importante destacar que a biodiversidade é bem coletivo, de modo que os valores sociais decorrentes desta riqueza exigem que o financiamento das pesquisas sejam públicos e que revertam para toda a sociedade, diferente do que vem ocorrendo, como explica Saragoussi (2002, p. 98):

\begin{abstract}
Para criar condições de tomada de decisões autônoma e soberana sobre os recursos genéticos e o seu uso público, seriam necessários investimentos em ciência e tecnologia nos países ricos em biodiversidade. Esses investimentos deveriam ser públicos, se quisermos que os resultados das pesquisas possam beneficiar toda a população e não somente os que podem pagar pelos produtos gerados ou aqueles que são alvos de medidas sociais compensatórias. No entanto, o que temos observado é o direcionamento da pesquisa pública para atender aos interesses de empresas privadas, por meio de restrição dos recursos públicos para ciência e tecnologia e direcionamento das prioridades de pesquisa pelos investimentos das empresas privadas feitos em laboratórios públicos.
\end{abstract}

É interessante observarmos, no decorrer desta análise, a necessidade de participação da sociedade nesta dinâmica que possibilitaria a mudança paradigmática necessária. Considerando as diferentes dimensões da cidadania - civil, política e social - emerge, nos albores do novo milênio, uma nova fase de participação cidadã: a ecológica. Neste sentido, o ser humano estabeleceria relações de deveres e obrigações com todos os membros da comunidade biótica, influenciando diretamente as estruturas e efeitos dos projetos e empreendimentos promovidos pela ação humana. A ciência política ainda não apreendeu um conceito completo acerca desta nova relação entre sociedade e natureza, embora seus efeitos já sejam previstos, como salientado por Smith (1998, p. 130-131):

\footnotetext{
A cidadania ecológica levará a espécie humana a uma reavaliação fundamental das suas capacidades para agir sobre o meio ambiente. A complexidade, a incerteza e a interconexão crescente de todas as coisas vivas, bem como os sistemas que sustentam a vida das mesmas, tornam a reavaliação das obrigações humanas ainda mais imperativas. Muitas escolhas pessoais básicas, anteriormente consideradas invioláveis, serão submetidas ao desafio. Isto envolve mais do que outra mudança na fronteira público-privado, pois significa a cedência da própria distinção. Numa situação deste tipo, as personificações institucionais das esferas privada e pública, ou seja, a sociedade civil e o Estado, estarão em dúvida.
} 
Evidencia-se que, para garantir que essas mudanças ocorram, é imprescindível uma nova visão do direito, que leve em conta os princípios da preservação da sociobiodiversidade, bem como o incentivo à sustentabilidade ambiental, econômica, cultural e social.

\section{CONSIDERAÇÕES FINAIS}

Diante do que foi exposto, fica evidente a necessidade de superação dos atuais processos de submissão e exploração a que são submetidos os povos dos países em desenvolvimento que são detentores de uma interação produtiva e harmônica com a biodiversidade que os cerca.

Para isso, é imprescindível, não só para a América Latina, mas para todos os países do Sul em que se identifica essa realidade, o desenvolvimento de uma perspectiva "PósColonial" que faça frente às tentativas do discurso hegemônico de padronizar a cultura, os métodos de produção e o conhecimento. A complementaridade de saberes entra em cena, como alternativa para mitigar os efeitos da rivalização entre o saber científico e o tradicional que surgiu pelos ideais lançados pelo movimento da pós-modernidade.

A realização do Ano da Biodiversidade, em 2010, bem como os recentes planos de iniciativa do governo representam a existência de uma movimentação positiva, tanto internacionalmente como dentro dos Estados, tendo em vista a promoção da exploração sustentável e equitativa da sociobiodiversidade. No entanto, a realidade mostra que é essencial uma iniciativa de exigência popular para que estes propósitos saiam do papel.

Torna-se pertinente, portanto, a emergência de uma visão jurídica que favoreça os direitos da sociobiodiversidade, visando a produção, o desenvolvimento e o consumo sustentável, bem como a construção de uma eco-cidadania no mundo globalizado. 


\section{REFERÊNCIAS}

Acordo TRIPs. Disponível em http://www.cultura.gov.br/site/wpcontent/uploads/2008/02/ac_trips.pdf. Acesso em 12/04/11

Agenda 21, cap. Mudança dos padrões de consumo. Disponível em http://www.cqgp.sp.gov.br/gt_licitacoes/publicacoes/AGENDA\%2021\%20GLOBAL\%20CA P\%C3\%8DTULO\%204.pdf. Acesso em 12/04/2011.

Ano Internacional da Biodiversidade. Disponível em http://www.peaunesco.com.br/BIO2010/Diretrizes_Gerais\%20\%20Ano\%20Internacional\%20da\%20Biodiversidade\%20-\%202010.pdf

ARAÚJO, Luis Ernani Bonesso de, Agricultura y Medioambiente: La Apropriación Del Conocimiento, em GUMUCIO, Cristián Parker e SAAVEDRA, Fernando Estenssoro (editores), El Desafio Del Conocimiento para América Latina, USACH, Santiago de Chile, 2010.

CAPRA, Fritjof. A Teia da Vida. São Paulo: Cultrix, 2001.

As conexões Ocultas: ciência para uma vida sustentável. São Paulo: Cultrix, $3^{\text {a }}$ ed. 2003.

CONFERÊNCIA DAS NAÇÕES UNIDAS PARA O MEIO AMBIENTE E O

DESENVOLVIMENTO. Convenção sobre Diversidade Biológica. Disponível na íntegra em http://www.onu-brasil.org.br/doc_cdb.php. Acesso em 12/04/2011

Decreto Legislativo $\quad \mathrm{n}^{\circ} 2 / 1994, \quad$ disponível em http://www.mct.gov.br/index.php/content/view/14925.html.

Decreto $\mathrm{N}^{\mathrm{o}} 2.519$ de 16 de março de 1998, disponível em http://www.planalto.gov.br/ccivil_03/decreto/D2519.htm. Acesso em 12/04/11.

DIEGUES, Antônio Carlos (Org.). Os Saberes tradicionais e a biodiversidade no Brasil. São Paulo: Núcleo de Pesquisas sobre Populações Humanas e Áreas Úmidas Brasileiras da Universidade de São Paulo (NUPAUB-USP); Brasília: Coordenadoria da Biodiversidade do Ministério do Meio Ambiente, dos Recursos Hídricos e da Amazônia Legal (COBIO-MMA), 2000. Disponível em: <http://www.mma.gov.br/estruturas/chm/_arquivos/saberes.pdf>. Acesso em: 14 jul. 2009

FIGUEIREDO, Guilherme José Purvin de. A questão ambiental no direito brasileiro. In: KISHI, Sandra Akemi Shimada. SILVA, Solange Teles da. SOARES, Inês Virgínia Prado. (org). Desafios do Direito Ambiental no Século XXI. Estudos em homenagem a Paulo Affonso Leme Machado. São Paulo: Malheiros, 2005, p.489. 
GUATTARI, Félix. As Três ecologias. Traduzido por Maria Cristina F. Bittencourt. Campinas: Papirus, 1990. Tradução de: Les trois écologies.

HARVEY, David. Condição Pós-moderna. Tradução de Adail Ubirajara Sobral e Maria Stela Gonçalves. São Paulo, Brasil: Edições Loyola, 1992. 11ª edição, 2002.

MACHADO, Paulo Affonso Leme. Direito Ambiental Brasileiro. 8 ed. São Paulo: Malheiros, 2000.

MATURANA, Humberto R.; VARELA, Francisco J. A árvore do conhecimento: as bases biológicas da compreensão humana. São Paulo: Athenas, 2001.

Medida Provisória $\quad \mathrm{n}^{\mathrm{o}}$ 2.186-16/2001. Disponível em http://www.planalto.gov.br/ccivil_03/mpv/2186-16.htm. Acesso em 12/04/2011.

MORIN, Edgar. Introdução ao pensamento complexo. Lisboa: Instituto Piaget, 2001.

Plano Nacional de Promoção das Cadeias de Produtos da Sociobiodiversidade. Disponível em http://comunidades.mda.gov.br/portal/saf/arquivos/view/sociobiodiversidade/PLANO_NACI ONAL_DA_SOCIOBIODIVERSIDADE-_julho-2009.pdf. Acesso em 12/04/2011.

SHIVA, Vandana, "The World on the Edge", em HUTTON, WILL e ANTHONY GIDDENS (orgs.). Global Capitalism, The New Press, Nova York, 2000.

Vozes, 2001.

Biopirataria: a pilhagem da natureza e do conhecimento. Petrópolis:

Monoculturas da mente: perspectivas da biodiversidade e da biotecnologia. São Paulo: Gaia, 2003.

SANTOS, Boaventura de Sousa (org). Reconhecer para libertar: os caminhos do cosmopolitismo cultural. Civilização Brasileira, 2003

Os processos de globalização. In: (Org.). A

Globalização e as ciências sociais. $3^{\mathrm{a}}$ edição, São Paulo: Cortez, 2005.

Semear outras soluções: os caminhos da biodiversidade e dos conhecimentos rivais. Rio de Janeiro: Civilização Brasileira, 2005.

SARAGOUSSI, Muriel. Direito de acesso à proteção e uso da biodiversidade. In: BORN, Rubens Harry (coord.). Diálogos entre as esferas global e local: contribuições de organizações não-governamentais e movimentos sociais brasileiros para a sustentabilidade, equidade e democracia planetária. São Paulo: Editora Fundação Peirópolis.

SMITH, Mark J. Manual de Ecologismo: Rumo à cidadania ecológica. Lisboa: Instituto Piaget, 1998. 